\title{
Crianças com Síndrome de Down e suas Interações Familiares
}

\author{
Nara Liana Pereira Silva \\ Maria Auxiliadora Dessen ${ }^{2}$ \\ Universidade de Brasilia
}

\begin{abstract}
Resumo
Crianças com deficiência exercem um impacto profundo sobre o funcionamento da família que necessita ser melhor investigado. Este estudo tem como objetivos a) descrever alguns aspectos do desenvolvimento e da vida familiar de crianças com síndrome de Down, segundo o relato dos genitores e b) identificar os padrões de interação familiar, destacando os subsistemas genitores-criança. Seis famílias, consistindo de pai, mãe e uma criança pré-escolar com síndrome de Down, foram selecionadas. As mães responderam um questionário e participaram de entrevistas semi-estruturadas com os pais, separadamente. Dezoito sessões de observação do comportamento foram conduzidas na residência das famílias, totalizando 171 minutos de gravação em vídeo de atividades livres. Os resultados mostraram que as atividades foram desenvolvidas predominantemente de forma "conjunta" e que as interações familiares foram caracterizadas pela "sincronia", "supervisão", "liderança" e "amistosidade". Os dados sugerem que, para compreender o funcionamento de famílias de crianças com síndrome de Down, faz-se necessário focalizar o papel do pai.

Palavras-chave: Interações familiares; síndrome de Down; observação direta do comportamento; crianças pré-escolares.
\end{abstract}

Children with Down Syndrome and their Family Interactions

Abstract

Disabled children exert strong impact on the families' dynamic that need to be better investigated. This study aims to a) describe some aspects of the Down syndrome children's development and family life according to parents and b) identify the patterns of family interaction, emphasising the parent-child subsystems. Six families consisting of father, mother and preschool child with Down syndrome were selected: to participate in this study. A questionnaire was answered by mothers and semi-structured interviews by mothers and fathers, separately. Eighteen behaviour observations were conducted in the families' residence consisting of 171 minutes of video recording of free home activity sessions. The results show that the activities were carried out by family members with predominance of the "joint participation". The family interactions were developed in a "synchronised" way, with "supervision", "leadership", and "friendship". Our data suggest the need of focusing on the role of the father in order to better understand the functioning of Down syndrome children's families.

Keywords: Family interactions; Down syndrome; direct observation of behaviour; preschool children.

As interações estabelecidas no microssistema família são as que trazem implicações mais significativas para o desenvolvimento da criança, embora outros sistemas sociais (Ex.: escola, local de trabalho dos genitores, clube) também contribuam para o seu desenvolvimento. Infelizmente, há uma escassez de trabalhos que focalizam este tema, em se tratando de crianças que apresentam algum tipo de deficiência, particularmente no Brasil (Dessen \& PereiraSilva, 2000). Em geral, há uma predominância de estudos que focalizam as interações desenvolvidas entre a mãe e sua criança com deficiência mental (DM) (Cielinski, Vaughn, Seifer \& Contreras, 1995; Colnago, 1991; Corter, Pepler, Stanhope \& Abramovitch, 1992; Landry, Garner, Pirie \& Swank, 1994; Lieberman, Padan-Belkin \& Harel, 1995;

Trabalho de dissertação de Mestrado da primeira autora, apresentado ao Instituto de Psicologia Universidade de Brasilia, sob orientação da segunda autora (Apoio CNPq).

${ }^{2}$ Endereço para correspondência: Laboratório de Desenvolvimento Familiar Instituto de Psicologia, Universidade de Brasilia, Campus Universitário Brasilia DF, 70910-900.E-mail:dessen@unb.br
Marfo, Dedrick \& Barbour, 1998; Roach, Barratt, Miller \& Leavitt, 1998; Sigolo, 1994; Vaughn \& cols., 1994). O subsistema pai-criança DM é pouco investigado (Herbert \& Carpenter, 1994; Hornby, 1995; Rodrigue, Morgan \& Geffken, 1992), indicando a necessidade de implementação não somente de mais estudos sobre este tema, mas também de estudos que incluam todos os membros da família (Dessen, 1997; Dessen \& Pereira-Silva, 2000; Kreppner, 2000)

Os estudos sobre as interações das crianças com síndrome de Down (SD) e seus genitores apresentam dados inconclusivos, não havendo, ainda, explicações para algumas inconsistências e contradições (Berger, 1990). Apesar da existência de algumas divergências, há dados consistentes no que tange, principalmente, a uma maior diretividade das mães de crianças DM em comparação com as mães de crianças com desenvolvimento normal (DN) quando em interação com suas crianças (Cielinski \& cols., 1995; Landry \& cols., 1994; Lieberman \& cols., 1995; Marfo \& cols., 1998; Sigolo, 1994, 2000). Segundo Landry e colaboradores, as 
diferenças entre os comportamentos interativos de crianças SD e DN estão relacionadas às demandas do contexto social, ao grupo de risco e à baixa habilidade de linguagem expressiva das crianças. De acordo com esses autores, as mães de crianças com SD são, também, significativamente mais intrusivas que as mães de crianças DN. Apesar desta intrusividade e diretividade, os resultados do estudo de Cielinski e colaboradores indicam não ter havido diferenças significativas entre os dois grupos de crianças, em se tratando da qualidade da brincadeira. Segundo Roach e colaboradores (1998), a alta freqüência do comportamento diretivo das mães não parece ter sido suficiente para impedir que crianças com SD e DN brincassem com objetos, não exercendo efeitos prejudiciais sobre a qualidade da brincadeira e sobre a vocalização das crianças com síndrome de Down.

Nas associações entre o gênero da criança DM e a diretividade da mãe, o estudo de Cielinski e colaboradores (1995) indicou que mães de meninas com síndrome de Down tendiam a ser mais diretivas que mães de meninas $\mathrm{DN}$, enquanto que mães de meninos $\mathrm{DN}$ mostraram-se mais diretivas que mães de meninas deste mesmo grupo No estudo de Roach e colaboradores (1998), as mães de crianças com SD foram mais diretivas com suas filhas do que com seus filhos, sugerindo que as interações entre a mãe e a filha, em geral, são caracterizadas por um maior controle materno que as interações entre a mãe e o filho.

Apesar de haver uma maior diretividade materna durante as interações mãe-criança DM, há também uma adequação dos comportamentos exibidos entre os parceiros durante os episódios interativos, isto é, a criança atende e responde ao comportamento de sua mãe e vice-versa, o que sugere uma adaptação mútua entre os comportamentos de ambas (Cielinski \& cols., 1995). No estudo de Colnago (1991), foi encontrado este mesmo padrão de interação durante três situações de observação (banho, papa e mamadeira), havendo freqüente estimulação por parte da mãe à sua criança $\mathrm{SD}$, bem como respostas mútuas entre a díade nesse momentos. Segundo Colnago, algumas situações favoreceram mais a interação, como no caso da papa, em que a mãe teve que procurar mais recursos para proporcionar a alimentação à criança. Além disso, as mães destas crianças exibiram, significativamente, altas freqüências de elogio quando comparadas às mães de crianças $\mathrm{DN}$, sugerindo que as adaptações destas mães às suas crianças pequenas com síndrome de Down foram adequadas (Cielinski \& cols., 1995; Lieberman \& cols., 1995; Roach \& cols., 1998).

Com relação ao engajamento dos genitores durante as interações com suas crianças DM, as mães engajam-se significativamente mais que os pais, conforme indicam alguns estudos (Floyd, Costigan \& Phillippe, 1997; Floyd \& Zmich, 1991; Sigman, Mundy, Sherman \& Ungerer, 1986). Além disso, os pais destas crianças apresentam comportamentos de comunicação significativamente menos positivos e altas taxas de reciprocidade negativa em comparação com pais de crianças com desenvolvimento normal e também com mães de crianças DM (Floyd \& cols., 1997; Floyd \& Zmich, 1991; Sigman \& cols., 1986). No entanto, Rodrigue e colaboradores (1992), investigando a adaptação psicossocial de pais de crianças autistas, com síndrome de Down e com desenvolvimento normal, não encontraram diferenças significativas entre os três grupos quanto aos cuidados dispensados aos filhos e a satisfação percebida pelos pais. Apesar de os pais de meninos relatarem maior satisfação com a paternidade que os pais de meninas, os resultados do estudo de Hornby (1995) não indicaram diferenças entre a adaptação dos pais às filhas e aos filhos com SD. Neste estudo, a adaptação do pai estava relacionada à sua satisfação com o apoio social recebido, à sua satisfação marital e às suas características de personalidade, mais do que às características de sua criança deficiente.

A severidade da deficiência é uma outra variável que tem sido destacada como exercendo influência no envolvimento e adaptação do pai à criança com deficiência. Contudo, a literatura mostra dados contraditórios a esse respeito, com algumas pesquisas apontando para um maior envolvimento, enquanto outras não mostram diferenças (Hornby, 1995; Lamb \& Billings, 1997). Os dados, portanto, refletem a inconsistência existente entre os estudos sobre as interações pai-criança DM, sugerindo a necessidade de mais pesquisas que incluam não somente o pai em seus planejamentos, mas outros componentes da família, particularmente os irmãos (Dessen \& Pereira-Silva, 2000). O papel do pai tem sido, recentemente, apontado como uma das tendências de pesquisa sobre as relações familiares (Dessen \& Lewis, 1998). Focalizar o subsistema pai-criança é fundamental para a compreensão do funcionamento da família e das interações desenvolvidas neste microssistema.

Assim, conhecer como se desenvolvem as interações entre crianças pré-escolares com síndrome de Down e os membros de sua família adquire importância crucial para a compreensão do desenvolvimento de tais crianças. Com este propósito, implementamos um estudo com o objetivo de: descrever as interações criança-mãe, criança-pai e criançamãe-pai em situação de atividade livre, focalizando: a) o conteúdo da interação, isto é, o tipo de atividade em que eles se engajam; b) os participantes, isto é, quais os membros familiares que se engajam em que tipo de atividade; c) a qualidade das interações familiares, através das dimensões de sincronia, supervisão, amistosidade e liderança. A identificação dos membros familiares responsáveis pelo início das interações e de alguns comportamentos emitidos pelos genitores e pela criança, apontados na literatura como 
característicos da interação de crianças DM com seus genitores também são descritos.

\section{Método}

\section{Participantes}

Participaram deste estudo 6 famílias compostas por mãe pai e criança com síndrome de Down, todos morando juntos em cidades satélites de Brasília $(n=5)$ ou no Plano Piloto $(n=1)$. Três crianças eram do sexo masculino e 3 do sexo feminino, com idades que variavam entre 2 a 3 anos e 5 meses, por ocasião da coleta de dados. Apenas uma criança não possuía irmão e, as demais, possuíam de um a cinco irmãos.

A idade média das mães era de 37 anos e a dos pais, 33 anos. As ocupações mencionadas pelos pais foram: radialista, administrador (aposentado), autônomo, militar, ajudante de obras e ajudante de serviços gerais. Quanto às mães, três não trabalhavam fora de casa, uma estava desempregada, uma era professora e a outra tinha cargo de técnico administrativo em órgão do governo. A renda familiar média era de 6,5 salários mínimos ${ }^{3}$. Com relação à escolaridade das mães, três possuíam o $1^{\circ}$ grau incompleto, uma o $2^{\circ}$ grau completo e duas possuíam o curso superior. Quanto aos pais, dois possuíam o $1^{\circ}$ grau incompleto, um o $1^{\circ}$ grau completo, um cursava a universidade e dois haviam completado o curso superior.

\section{Procedimentos}

A coleta de dados foi efetuada pela pesquisadora, na própria residência das famílias. Cada família foi visitada, em média, 5 vezes durante o período de 1 mês. Foram utilizadas 3 técnicas para a coleta de dados: questionário, entrevistas semi-estruturadas e observação direta do comportamento, usando os recursos da tecnologia de vídeo. Primeiramente, foi realizada a aplicação do questionário à mãe com a finalidade de caracterizar a família. Foram coletadas informações sobre idade e escolaridade, renda familiar, ocupação e estado civil dos genitores, contatos sociais da família e identificação dos responsáveis pelas tarefas rotineiras da casa e dos cuidados com a criança.

As entrevistas foram realizadas com a mãe e com o pai, separadamente, e registradas em um gravador da marca Panasonic, modelo RQ-2102. A entrevista abordou os seguintes temas: a) história de vida da criança: gravidez, parto, desenvolvimento psicomotor, sociabilidade, escolaridade e doenças; b) informações sobre o diagnóstico

Salário mínimo vigente à época da coleta de dados era de $\mathrm{R} \$ 136,00$. Uma família foi excluída do cálculo médio por apresentar uma renda correspondente a 88 salários mínimos. da criança: iniciativas tomadas e reação dos genitores ao diagnóstico; c) informações sobre os hábitos e costumes da criança e da família; d) características comportamentais e emocionais da criança; e e) expectativas dos genitores em relação à criança com síndrome de Down. A entrevista realizada com o pai da criança incluiu questões relativas ao papel desempenhado por ele no contexto familiar, além dos temas $b, d$ e $e$ investigados na entrevista realizada com a mãe.

As sessões de observação foram planejadas com o objetivo de descrever as interações diádicas e triádicas desenvolvidas entre a criança e a mãe $(\mathrm{C}-\mathrm{M})$, a criança e o pai (C-P) e a criança, a mãe e o pai (C-M-P), quando a tarefa principal dos participantes era "interagir", ou seja, quando em atividades livres. Atividade livre foi definida como "toda e qualquer atividade de lazer, tais como assistir à televisão, contar histórias, brincar, excluindo-se, assim, quaisquer atividades de cuidados rotineiros com a casa (arrumar cozinha, fazer almoço) e com a higiene da criança" (Dessen, 1992, p. 56)

A criança com síndrome de Down foi, então, observada com cada um dos genitores (C-M e C-P), separadamente, e com ambos (C-M-P), totalizando 18 sessões de gravação para as 6 famílias. Em cada visita foram gravadas, no máximo, duas sessões de observação, de acordo com a disponibilidade da família, com duração média de $9 \mathrm{~min} 51 \mathrm{~s}$, perfazendo um total de $171 \mathrm{~min} 33 \mathrm{~s}$ de gravação. Os locais e os períodos do dia para a realização das observações foram escolhidos pela própria família. Os locais foram variados: sala, quarto do casal ou das crianças, escritório, cozinha e quintal. Quanto aos períodos, a maioria das gravações foi efetuada no período da tarde.

As fitas de vídeo foram transcritas de acordo com o modelo proposto por Dessen $(1984,1992)$ : a) as atividades desenvolvidas (conteúdo); b) estrutura de participação nas interações; c) os tipos de transição de uma atividade para outra; d) a qualidade dos episódios interacionais; e e) as categorias comportamentais. O registro utilizado foi o seqüencial categórico, tanto para as atividades e suas especificações, quanto para a qualidade dos episódios interativos. O sistema de categorias de Dessen foi adaptado para este estudo, tendo sido acrescentadas as categorias referentes a "Brincadeiras" ('Andar de bicicleta', 'Com animais'), 'Ouvir música' e 'Socializar' ('Referente a cuidados diários com o corpo', 'Envolvendo aspectos do ambiente familiar e social' e 'Envolvendo aspectos do ambiente físico'). Foram retiradas as categorias relativas aos 'Jogos', 'Brincadeira de faz-de-conta', aloumas categorias de 'Socialização', de 'Dispensar atenção ao bebê', 'Realização de tarefas rotineiras' e as categorias de 'Contextualização da atividade'. As categorias 'Brincadeiras com computador e objetos', 
Tabela 1

Dicionário de Categorias

\begin{tabular}{|c|c|}
\hline Códigos & Significados \\
\hline$\overline{1-\mathrm{Lu}}$ & I - Atividades lúdicas \\
\hline 1. $\mathrm{Br}$ & Brincadeiras \\
\hline 1.1. $\mathrm{BrOb}$ & Com computador, brinquedos e objetos em geral \\
\hline 1.2. $\mathrm{BrCo}$ & Envolvendo a manipulação de partes do corpo \\
\hline 1.3. BrEs & Estouvadas \\
\hline 1.4. BrAt & Brincadeira de atividades escolares \\
\hline 1.5. $\mathrm{BrBi}$ & Andar de bicicleta \\
\hline 1.6. $\mathrm{BrAn}$ & Brincadeira com animais \\
\hline 2. Ar & Atividades artísticas \\
\hline 2.1. $\mathrm{Ca}$ & Canto \\
\hline 2.2. $\mathrm{Da}$ & Dança \\
\hline 3. TV & Assistir à televisão \\
\hline 3.1. $\mathrm{Sl}$ & Silenciosamente \\
\hline 3.2. $\mathrm{Cn}$ & Conversando \\
\hline 4. $\mathrm{Mu}$ & Ouvir música \\
\hline 5. $\mathrm{Hi}$ & Contar histórias \\
\hline 6. $\mathrm{Cv}$ & Conversar \\
\hline 6.1. Fa & Família \\
\hline 6.2. Et & Estímulos presentes \\
\hline 6.3. An & Sobre desenhos animados e animais \\
\hline 7. So & Socializar \\
\hline 7.1. Cp & Referente a cuidados diários com o corpo \\
\hline 7.2. Fs & Envolve aspectos do ambiente familiar e social em geral \\
\hline 7.3. Fi & Envolve aspectos do ambiente físico \\
\hline 7.4. $\mathrm{Rl}$ & Envolve aspectos do relacionamento social \\
\hline 8. Cd & Cuidados dispensados à criança \\
\hline \multicolumn{2}{|c|}{ II - Tipos de transição } \\
\hline 1. TD & Transição direta \\
\hline 2. TDG & Transição pela dissolução do grupo \\
\hline 3. TN & Transição por negociação \\
\hline 4. IS & Interrupção da sessão \\
\hline \multicolumn{2}{|c|}{ III - Estrutura de participação } \\
\hline 1. In & Individual \\
\hline 2. Gr: & Grupal \\
\hline 2.1. $\mathrm{Pl}$ & Paralela \\
\hline 2.2. $\mathrm{Cj}$ & Conjunta \\
\hline \multicolumn{2}{|c|}{ IV - Qualidade dos episódios de interação } \\
\hline 1. Si & Sincronia \\
\hline 1.1. Si & Com sincronia \\
\hline 1.2. Ssi & Sem sincronia \\
\hline 2. Sv & Supervisão \\
\hline 2.1. Sv & Com supervisão \\
\hline 2.2. Ssv & Sem supervisão \\
\hline 3. A & Afetividade \\
\hline 3.1. A & Amistosa, sem emissão de comportamentos afetivos \\
\hline 3.2. Aaf & Amistosa, com emissão de comportamentos afetivos \\
\hline
\end{tabular}




\begin{tabular}{ll}
\hline 3.3. C & Conflituosa, sem emissão de comportamentos agressivos \\
3.4. Cag & Conflituosa, com emissão de comportamentos agressivos \\
4. Ld & Liderança \\
4.1. Ld & Com liderança \\
4.2. Sld & Sem liderança \\
\hline & V-Categorias comportamentais \\
\hline 1. St/sg & Solicitar/sugerir \\
2. $\mathrm{Or}$ & Ordenar \\
3. $\mathrm{Pr}$ & Proibir \\
4. $\mathrm{Od}$ & Obedecer \\
4.1. OdSt & Obedecer solicitação/sugestão \\
4.2. OdOr & Obedecer ordem \\
5. $\mathrm{Rj}$ & Rejeitar \\
6. El & Elogiar \\
7. $\mathrm{Im}$ & Imitar \\
\hline
\end{tabular}

Nota. Sistema de categorias adaptado de Dessen $(1984,1992)$.

'Cuidados dispensados à criança' e aquelas referentes aos comportamentos emitidos pelos genitores e pela criança foram redefinidas, resultando, assim, no sistema observacional definitivo. A Tabela 1 apresenta as categorias e seus respectivos códigos.

O índice de concordância entre observadores foi calculado com base no registro de $16,6 \%$ das sessões de observação, realizado por outro observador treinado em Observação Direta do Comportamento. Este índice foi calculado para cada uma das dimensões de categorias (atividades, estrutura de participação, transições, qualidade das interações e categorias comportamentais) e para o conjunto das dimensões, fornecendo um índice global de concordância. Os índices obtidos foram: a) atividades realizadas: $75 \%$; b) estrutura de participação: $64,5 \%$; c) transições: $60 \%$; d) qualidade das interações: $63 \%$; e) categorias comportamentais: $79 \%$. O índice global encontrado foi de $68,7 \%$.

\section{Resultados}

Os resultados dos relatos verbais são descritos agrupando-se os dados obtidos por meio dos questionários e das entrevistas semi-estruturadas, visando uma integração dos aspectos relevantes a respeito das crianças com síndrome de Down e de suas famílias. Os dados observacionais focalizam os tipos de atividades desenvolvidas pela criança e seus genitores, a estrutura de participação dos membros familiares e a responsabilidade pelo início dos episódios interativos, as transições de uma atividade para outra, a qualidade das interações e os comportamentos emitidos

Psicologia: Reflexão e Crítica, 2003, 16(3), pp. 503-514 pela criança e pelos genitores, durante o desenvolvimento das atividades.

\section{A Rotina das Famílias e o Desenvolvimento das Crianças SD}

A rotina das famílias, durante a semana, era semelhante, isto é, o pai ou ambos os genitores trabalhavam o dia inteiro, retornando à noite, enquanto as crianças com síndrome de Down freqüentavam o Programa de Estimulação Precoce do governo do Distrito Federal, em um período do dia. Apenas uma criança freqüentava, também, o ensino regular (maternal) no outro período. Os irmãos estudavam $(n=9)$ ou ficavam em casa com a mãe durante o dia todo $(n=2)$. As atividades de lazer, desenvolvidas fora do ambiente de casa, consistiam em visitas a parentes, passeios a parques, visitas ao zoológico e a shopping centers. As atividades realizadas no ambiente de casa eram assistir à televisão ou brincar com as crianças.

Com relação à história pessoal das crianças, a maioria das mães $(n=4)$ afirmou que, embora a gravidez não tivesse sido planejada, esta foi aceita com satisfação pelo casal. O período de gravidez foi considerado tranqüilo e calmo pela maioria das mães $(n=4)$, e nenhuma delas sabia que a criança tinha síndrome de Down, nessa ocasião. Todas as crianças nasceram na cidade de Brasília, em boas condições de saúde, sendo duas de parto normal e quatro de parto cesariana. As crianças foram amamentadas ao seio, exceto uma, pelo fato de a mãe ter sido hospitalizada no período logo após o parto. Quatro delas ainda faziam uso da mamadeira, por ocasião da coleta de dados.

Embora não tenham sido relatados problemas em relação à passagem de ingestão dos alimentos pastosos para os sólidos, duas mães disseram que suas crianças 
engasgavam com facilidade. Todas as crianças foram descritas como possuidoras de um "bom apetite", com exceção de uma, que rejeitou a amamentação ao seio e outros tipos de alimentos, no início da introdução dos mesmos, passando a aceitá-los posteriormente. Com relação ao sono, a maioria das crianças dormia tranqüilamente quando bebês.

Quanto ao desenvolvimento motor, observou-se que este ocorreu de forma distinta para cada criança. Segundo o relato das mães, duas crianças sustentaram a cabeça com 3 meses, duas com 8 meses e duas mães não se lembraram do período em que suas crianças sustentaram a cabeça. Três crianças sentaram-se com 10 meses e duas adquiriram essa capacidade um pouco mais cedo, aos 7 meses e uma mãe não se lembrou da idade em que seu filho começou a sentar-se. Quatro crianças engatinharam após 1 ano de idade, tendo duas iniciado esse processo aos 8 meses. Metade das crianças começou a andar ao completar 1 ano e 6 meses, enquanto outras duas, só após 2 anos e 2 meses. Três crianças eram capazes de correr, embora não fossem capazes de pular à época da coleta de dados. Com relação ao desenvolvimento da linguagem, as crianças pronunciavam, embora incorretamente, apenas palavras isoladas, tais como 'mamãe', 'papai', 'vovó' etc..

Com relação aos antecedentes pessoais na família, três mães relataram não haver casos de síndrome de Down ou qualquer outro tipo de deficiência ou doença mental ou, ainda, alcoolismo. Contudo, duas delas relataram casos de parentes maternos com síndrome de Down e uma outra casos de doenças mentais entre parentes paternos.

Tabela 2

Tïpos de Atividades Desenvolvidas por Genitores e suas Crianças, por Situação de Observação

\begin{tabular}{|c|c|c|c|c|c|c|c|c|}
\hline \multirow{3}{*}{ Atividades desenvolvidas } & \multicolumn{6}{|c|}{ Situação de observação } & \multirow{3}{*}{$\begin{array}{l}\text { Total } \\
\text { Freq. }\end{array}$} & \multirow[b]{3}{*}{$\%$} \\
\hline & \multicolumn{2}{|c|}{$\mathrm{C}-\mathrm{M}$} & \multicolumn{2}{|c|}{ C-P } & \multicolumn{2}{|c|}{ C-M-P } & & \\
\hline & Freq. & $\%$ & Freq. & $\%$ & Freq. & $\%$ & & \\
\hline \multicolumn{9}{|l|}{ Brincadeiras } \\
\hline Com objetos & 11 & 20,0 & 12 & 22,2 & 12 & 25,0 & 35 & 22,2 \\
\hline De manipular o corpo & 04 & 7,0 & 09 & 17,0 & 03 & 6,3 & 16 & 10,0 \\
\hline Com animais & 02 & 3,6 & - & - & 02 & 4,2 & 04 & 2,5 \\
\hline De atividades escolares & - & - & 01 & 1,8 & - & - & 01 & 0,6 \\
\hline De bicicleta & - & - & 01 & 1,8 & 01 & 2,0 & 02 & 1,3 \\
\hline Estouvadas & - & - & 01 & 1,8 & 02 & 4,2 & 03 & 2,0 \\
\hline Subtotal & 17 & 30,6 & 24 & 44,6 & 20 & 41,7 & 61 & 38,6 \\
\hline \multicolumn{9}{|l|}{ Artísticas } \\
\hline Canto & 04 & 7,0 & 01 & 1,8 & 01 & 2,0 & 06 & 3,8 \\
\hline Dança & 09 & 16,0 & 04 & 7,4 & 04 & 8,3 & 17 & 10,7 \\
\hline Subtotal & 13 & 23,0 & 05 & 9,2 & 05 & 10,3 & 23 & 14,5 \\
\hline \multicolumn{9}{|l|}{ Assistir à televisão } \\
\hline TV conversando & 01 & 1,7 & - & - & - & - & 01 & 0,6 \\
\hline Ouvir música & - & - & 02 & 3,7 & - & - & 02 & 1,3 \\
\hline Contar histórias & 07 & 12,5 & - & - & 03 & 6,3 & 10 & 6,3 \\
\hline \multicolumn{9}{|l|}{ Conversar } \\
\hline Sobre família & 01 & 1,7 & - & - & 03 & 6,3 & 04 & 2,5 \\
\hline Sobre estímulos externos & 08 & 14,5 & 11 & 20,4 & 11 & 23,0 & 30 & 18,9 \\
\hline Subtotal & 09 & 16,2 & 11 & 20,4 & 14 & 29,3 & 34 & 21,4 \\
\hline \multicolumn{9}{|l|}{ Socialização } \\
\hline Ambiente físico & 01 & 1,7 & 04 & 7,4 & 03 & 6,3 & 08 & 5,0 \\
\hline Ambiente familiar e social & 02 & 3,6 & 01 & 1,8 & 01 & 2,0 & 04 & 2,5 \\
\hline Sobre cuidados com o corpo & 01 & 1,7 & 04 & 7,4 & 01 & 2,0 & 06 & 3,8 \\
\hline Subtotal & 04 & 7,0 & 09 & 16,6 & 05 & 10,3 & 18 & 11,3 \\
\hline Cuidados dispensados à criança & 05 & 9,0 & 03 & 5,5 & 01 & 2,0 & 09 & 6,0 \\
\hline Total & 56 & 100 & 54 & 100 & 48 & 100 & 158 & 100 \\
\hline
\end{tabular}


Como as Famílias Reagiram ao Diagnóstico da Criança?

A suspeita de que a criança tivesse síndrome de Down foi revelada pelo médico às famílias, logo após o nascimento da criança. A reação imediata das mães a essa suspeita foi, principalmente, de preocupação; elas se perguntavam: "Como será minha criança?". Os pais, por sua vez, apresentaram reações diversificadas, tais como tristeza, estranheza, choque e até aceitação. Entretanto, todos os genitores relataram aceitar suas crianças, por ocasião da coleta de dados.

$\mathrm{Na}$ opinião das famílias, os médicos "não souberam anunciar corretamente o diagnóstico", favorecendo o aumento de "fantasias" acerca da síndrome de Down. Os genitores reconheceram não ter conhecimentos sobre a referida síndrome, por ocasião do nascimento da criança, o que ocorreu posteriormente, pela necessidade de conviver com ela. Algumas famílias ainda achavam que não possuíam conhecimento suficiente sobre a SD que as capacitassem a lidar com a criança de uma maneira mais adequada, embora todas reconhecessem a necessidade da estimulação precoce para o desenvolvimento da sua criança.

Após o diagnóstico, as famílias procuraram ajuda, por iniciativa própria, recorrendo, principalmente, ao Programa de Estimulação Precoce da Secretaria de Estado e Educação do Distrito Federal. Os genitores procuraram obter informações por meio de outras fontes de ajuda como livros e revistas e através de familias que também possuíam crianças com síndrome de Down. Na maioria das famílias, a procura por ajuda envolveu tanto a mãe quanto o pai.

Como são as Interações entre os Genitores e suas Crianças com Síndrome de Down?

As famílias desenvolvem atividades diversificadas, havendo predominância das atividades 'Lúdicas' em detrimento das demais (ver Tabela 2).

As atividades realizadas com mais freqüência foram as 'Brincadeiras', seguidas por 'Conversar', 'Atividades Artísticas'

Tabela 3

Tipos de Participação durante o Desenvolvimento das Atividades, por Situação de Observação

\begin{tabular}{lccccccccc}
\hline \multirow{2}{*}{ Tipos de participação } & \multicolumn{3}{c}{ Membros envolvidos nas atividades } & \multicolumn{3}{c}{ C-M-P } & Total \\
& Freq. & $\%$ & Freq. & $\%$ & Freq. & $\%$ & Freq. & $\%$ \\
\hline Conjunta & 57 & 67,0 & 57 & 67,8 & 63 & 77 & 177 & 70,5 \\
Paralela & 13 & 15,3 & 12 & 14,2 & 14 & 17 & 39 & 15,5 \\
Individual & 15 & 17,7 & 15 & 18,0 & 05 & 6 & 35 & 14,0 \\
\hline Total & 85 & 100 & 84 & 100 & 82 & 100 & 251 & 100 \\
\hline
\end{tabular}

Psicologia: Reflexão e Crítica, 2003, 16(3), pp. 503-514 e 'Socialização'. As 'Brincadeiras com Objetos’ e 'Brincadeiras de Manipular o Corpo' foram as preferidas pelas famílias. Embora tenha sido observado uma similaridade em relação aos tipos de atividades desenvolvidas nas situações diádicas (C-M e C-P) e triádicas (C-M-P), as 'Brincadeiras' foram mais freqüentes nas situações diádicas C-P que nas C-M.

As atividades foram desenvolvidas mais em 'Grupo' que 'Individualmente' (ver Tabela 3). Estando em "Grupo", modo "Conjunto" mais do que "Paralelo", conforme mostra a Tabela 3.

Apesar de as famílias apresentarem similaridades quanto aos estilos de participação, diferenças sutis foram observadas entre elas (ver Figura 1). Por exemplo, a família F4 foi a que apresentou maior freqüência de participação 'Conjunta' (90\%), não tendo sido registrada nenhuma participação 'Individual', indicando que seu estilo de interagir é predominantemente em 'Grupo'. A família F5, apesar de ter interagido freqüentemente em 'Conjunto' (69\%), foi a que apresentou a maior freqüência de participação 'Individual' (26\%). Já, a família F6 destacou-se por ter apresentado um estilo de participação misto, isto é, ora 'Conjunto' (54\%), ora 'Paralelo' (30\%) e ora 'Individual' $(16 \%)$.

G Conjunta m $\mathbb{m}$ Paralela Individual

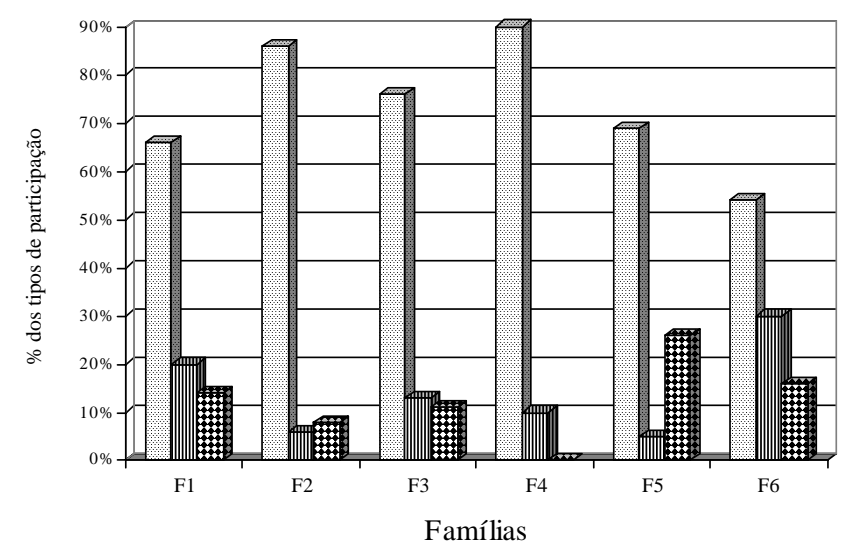

Figura 1. Tipos de participação na atividade, por família. os membros familiares participavam das atividades de 
Durante a realização de atividades, tanto o pai (38\%) quanto a mãe $(37 \%)$ iniciaram, com mais freqüência, as interações, enquanto a criança foi responsável por um percentual menor de iniciações $(25 \%)$, conforme pode ser observado na Figura 2.

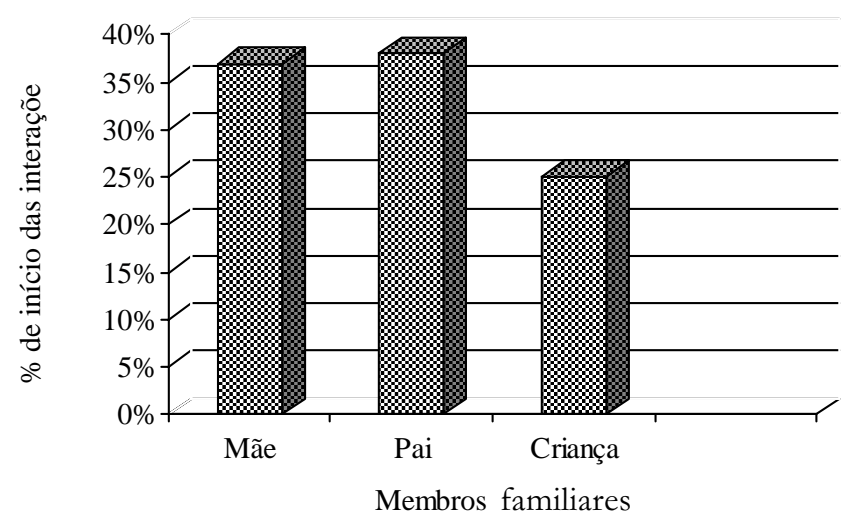

Figura 2. Responsabilidade pelo início de interações.

Como Ocorrem as Mudanças de Atividades?

As mudanças de uma atividade para outra ocorreram mais freqüentemente de forma 'Direta' (56,2\%) que pela 'Dissolução do Grupo' (23,6\%) ou pela 'Negociação' (14\%). A Figura 3 apresenta os percentuais de cada tipo de transição ocorrido nas situações de observação diádicas (C-M e C-P) e triádicas (C-M-P).

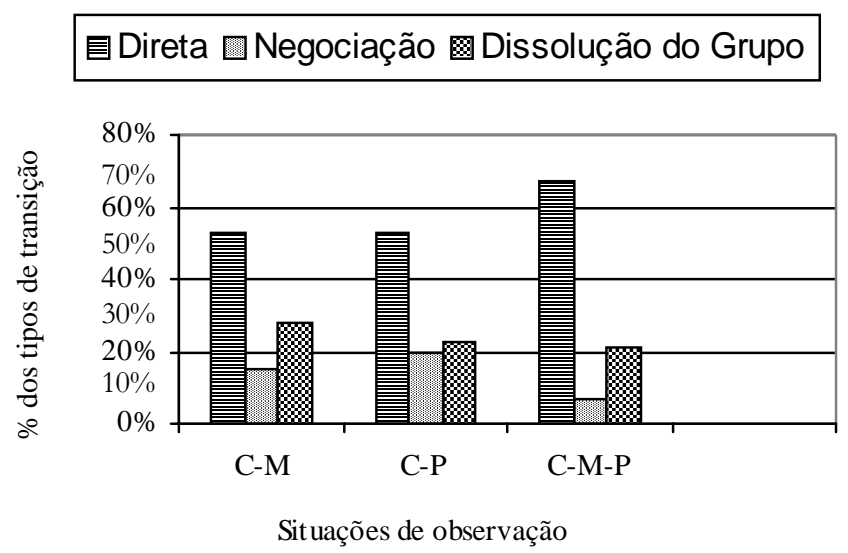

Figura 3. Tipos de transição de uma atividade para outra, por situação de observação.

A ‘Transição Direta’ ocorreu mais freqüentemente nas situações triádicas (C-M-P: 67\%) que nas situações diádicas (C-M: 53\% e C-P: 53\%). As 'Negociações', embora pouco freqüentes em todas as situações, ocorreram mais nas situações diádicas C-P (20\%) e C-M (15\%) que nas triádicas C-M-P (7\%). Já a 'Dissolução do grupo' ocorreu mais freqüentemente na situação C-M (28\%).

A Qualidade das Interações entre Genitores-Criança com SD

As interações entre a criança e seus genitores caracterizaram-se pela 'Sincronia', 'Supervisão', 'Amistosidade' e 'Liderança' (ver Tabela 4).

Tabela 4

Categorias de Qualidade das Interações com Especificação dos Subsistemas Familiares

\begin{tabular}{|c|c|c|c|c|c|c|c|c|}
\hline \multirow{3}{*}{$\begin{array}{l}\text { Dimensões de qualidade da } \\
\text { interação }\end{array}$} & \multicolumn{6}{|c|}{ Subsistemas Familiares } & \multirow{2}{*}{\multicolumn{2}{|c|}{ Total }} \\
\hline & \multicolumn{2}{|c|}{$\mathrm{C}-\mathrm{M}$} & \multicolumn{2}{|c|}{ C-P } & \multicolumn{2}{|c|}{ C-M-P } & & \\
\hline & Freq. & $\%$ & Freq. & $\%$ & Freq. & $\%$ & Freq. & $\%$ \\
\hline Sincronia & 115 & 76,7 & 112 & 83,0 & 94 & 67,0 & 321 & 75,5 \\
\hline Sem sincronia & 35 & 23,3 & 23 & 17,0 & 46 & 33,0 & 104 & 24,5 \\
\hline Supervisão & 149 & 99,3 & 131 & 97,0 & 138 & 98,5 & 35 & 98,3 \\
\hline Sem supervisão & 01 & 0,7 & 04 & 3,0 & 02 & 1,5 & 07 & 1,7 \\
\hline Amistosa & 144 & 96,0 & 109 & 80,7 & 131 & 93,6 & 384 & 90,3 \\
\hline Conflituosa & 06 & 4,0 & 26 & 19,3 & 09 & 6,4 & 41 & 9,7 \\
\hline Com liderança & 145 & 96,7 & 121 & 89,6 & 136 & 97,0 & 402 & 94,6 \\
\hline Sem liderança & 05 & 3,3 & 14 & 10,4 & 04 & 3,0 & 23 & 5,4 \\
\hline
\end{tabular}

Nota. Cada dimensão totaliza 100\%, uma vez que suas categorias são mutuamente exclusivas. 
As interações diádicas desenvolvidas entre a criança e a mãe ou o pai e as interações triádicas, envolvendo ambos os genitores e a criança mantiveram o mesmo padrão, caracterizando-se pela 'Sincronia', 'Supervisão', 'Amistosidade' e 'Liderança'. No entanto, ocorreram algumas diferenças entre os subsistemas diádicos e entre estes e o subsistema triádico, denotando algumas especificidades. As interações entre a díade C-P foram mais "Conflituosas" e "Sem Liderança”" que entre a díade C-M. Quando a criança, a mãe e o pai estavam interagindo juntos, os episódios interativos foram menos freqüentemente "Sincrônicos" comparados com os subsistemas diádicos, isto é, quando a criança estava interagindo só com a mãe ou só com o pai.

A emissão de comportamentos afetivos durante os episódios "Amistosos" foram pouco freqüentes, o mesmo ocorrendo em relação à emissão de comportamentos agressivos durante os episódios "Conflituosos". A identificação do membro familiar responsável pela emissão de tais comportamentos mostrou que, nas interações "Amistosas", as crianças foram as maiores responsáveis pela emissão de comportamentos afetivos. Isto ocorreu tanto nas interações diádicas, quanto nas interações triádicas. Nas interações "Conflituosas", somente as crianças emitiram comportamentos agressivo (ver Figura 4).

Embora os episódios de interação com emissão de comportamentos afetivos e agressivos tenham sido pouco freqüentes, foi possível identificar que, dentre os genitores,

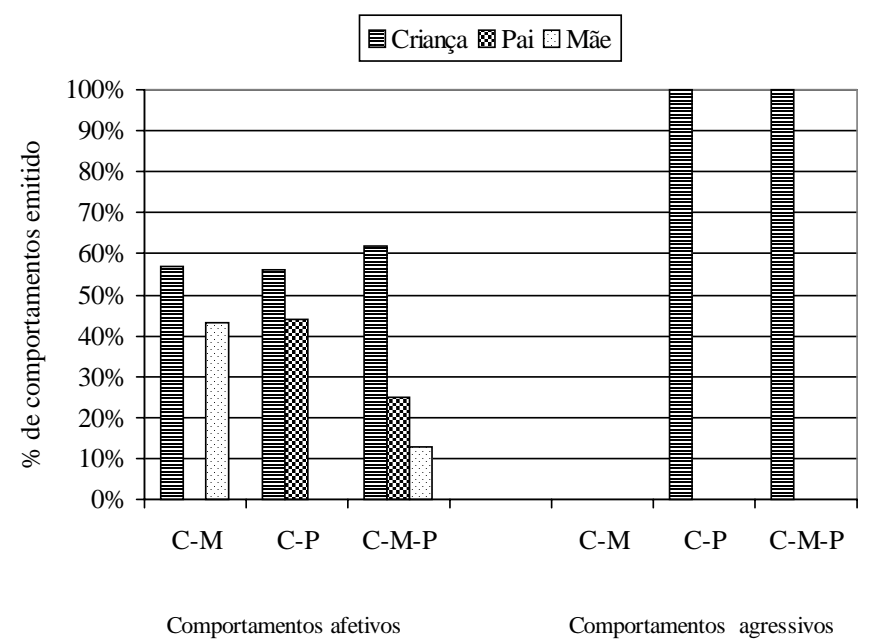

Figura 4. Membros familiares responsáveis pela emissão de comportamentos afetivos e agressivos, durante episódios de interação diádicos e triádicos.

foram os pais que emitiram mais freqüentemente comportamentos afetivos que as mães. Por outro lado, não foi observada a emissão de comportamentos agressivos nem pela mãe, nem pela criança durante as interações C-M.

Psicologia: Reflexão e Crítica, 2003, 16(3), pp. 503-514
A "Liderança" foi exercida predominantemente pelos genitores, tanto nas interações diádicas $(\mathrm{M}=85 \% ; \mathrm{P}=73 \%)$ como nas triádicas $(\mathrm{M}=43 \% ; \mathrm{P}=36 \%)$. A criança liderou apenas $15 \%$ dos episódios de interação com a mãe, enquanto que com o pai, a sua liderança foi um pouco mais freqüente (27\%). Nas interações triádicas, a criança liderou 21\% dos episódios (ver Figura 5).

Durante as interações desenvolvidas entre a criança e seus genitores, o comportamento de "Solicitar/Sugerir" foi mais freqüentemente emitido pelos genitores que pelas

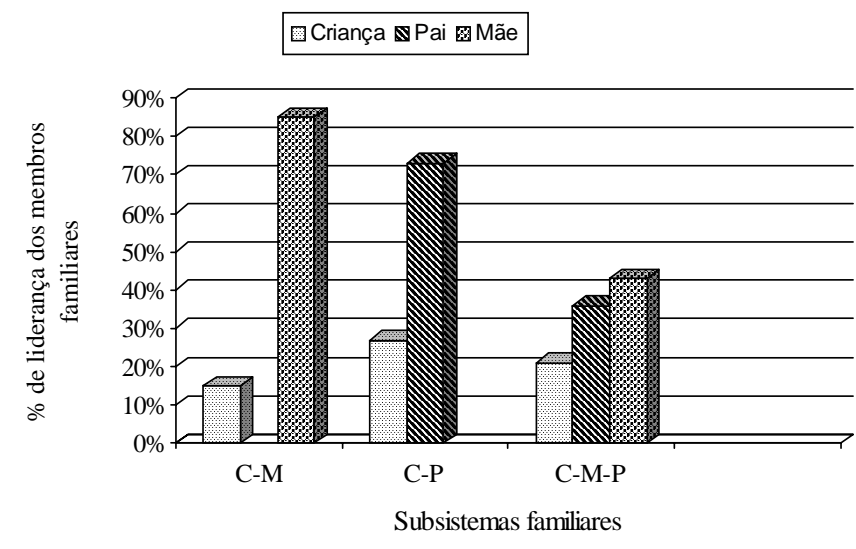

Figura 5. Liderança exercida pelos genitores e pela criança, durante episódios de interação diádicos e triádicos

crianças. Estas, por sua vez, 'rejeitaram' mais do que 'obedeceram' os comandos de seus genitores. A análise das reações das crianças frente aos comandos de cada genitor mostrou que estas 'rejeitavam' os comandos da mãe e do pai em proporções similares. Os comandos da criança foram 'Obedecidos' mais freqüentemente pela mãe $(89 \%)$ do que pelo pai $(79 \%)$, enquanto que as 'Rejeições' aos comandos do/da filho/filha foram mais freqüentes por parte do pai $(21 \%)$ do que da mãe $(11 \%)$.

Quais são as Expectativas dos Genitores Quanto ao Futuro de suas Crianças?

Todos os genitores esperam que suas crianças sejam independentes e que apresentem um desenvolvimento motor adequado, sendo capazes de praticar qualquer esporte e movimentar-se sem restrições. A maioria acredita que seu filho fará algum curso, seja o $1^{\circ}$ grau, seja um curso profissionalizante. Para um pai, a criança terá "facilidade nos estudos", conseguindo concluir um curso superior e ser um expoente na área que escolher. Os genitores demonstraram preocupação em relação à profissionalização de suas crianças, enfatizando o desejo de que elas tivessem uma profissão e que a exercessem, embora não especificassem qual. Quanto aos relacionamentos interpessoais com pessoas do sexo 
oposto, a maioria das mães $(n=4)$ espera que suas crianças possam namorar e até casar, embora acreditem que isto dependerá do próprio desenvolvimento da criança.

\section{Discussão}

A inconsistência nos relatos verbais sobre sentimentos, crenças e expectativas em relação à criança e ao seu futuro denota, claramente, a dificuldade dos genitores em aceitar a síndrome e em integrar a criança ao grupo familiar. $\mathrm{O}$ desejo de 'fazer de tudo' para melhorar o desempenho de sua criança, ao mesmo tempo em que ignoram as suas limitações, mostram que o conflito e as dificuldades que as famílias enfrentam ao lidar com a situação de ter uma criança com síndrome de Down são aspectos importantes do funcionamento dessas famílias. Provavelmente, o empreendimento em propiciar 'tudo' para a melhoria da criança pode ser uma tentativa de aliviar o sentimento de culpa vivenciado por eles, bem como de vencer as limitações provocadas pela síndrome (Casarin, 1999).

A síndrome de Down acarreta uma série de alterações orgânicas, como as endocrinológicas, oftalmológicas, gastrointestinais, auditivas, imunológicas etc., além da epilepsia e da doença de Alzheimer (Schwartzman, 1999a, 1999b). Embora as mães tenham relatado que suas crianças ficavam freqüentemente doentes, apenas uma delas percebia a filha como tendo um "organismo mais frágil e sensível" que as demais. No entanto, as infecções das vias aéreas superiores, que provocam gripes, bronquites e pneumonias, são doenças comuns em Brasília, em função do clima seco na maio parte do ano; por isso, não podemos afirmar que estas crianças sejam mais suscetíveis a doenças.

Os relatos dos questionários e das entrevistas apontam para uma heterogeneidade nos modos de vida das famílias; contudo, esta heterogeneidade parece ser decorrente de seus níveis sócio-econômicos e culturais diferenciados Três famílias freqüentavam um ambiente social e intelectual aparentemente mais rico em recursos que as outras três. O nível sócio-econômico parece, também, desempenhar um papel importante no que tange à procura disponibilidade de recursos para enfrentar a situação de se ter uma criança com síndrome de Down. Por exemplo, ao saberem do diagnóstico, as famílias mais favorecidas procuraram outras fontes de informação sobre a síndrome (revistas, instituições especializadas, famílias com criança com síndrome de Down), além dos médicos. Contudo, as menos favorecidas limitaram-se às poucas informações fornecidas pelo médico e pelo Programa de Estimulação Precoce. Apesar de as famílias deste estudo conhecerem pouco sobre a síndrome de Down, elas acreditavam na importância e na necessidade de um programa de estimulação precoce para a promoção do desenvolvimento da sua criança.

Segundo as mães e os pais deste estudo, a forma como os médicos deram a notícia do diagnóstico da criança não foi adequada e, devido a isto, suas fantasias a respeito da síndrome aumentaram, uma vez que não esperavam uma criança com síndrome de Down e nem tinham conhecimento suficiente sobre o assunto. Assim, é de fundamental importância o apoio de uma equipe multiprofissional, incluindo o psicólogo, no momento de comunicar o diagnóstico aos genitores. Esse primeiro momento parece ser o mais difícil para as famílias (Bolsanello, 1998; Brito \& Dessen, 1999; Casarin, 1999), que devem, aos poucos, e, dependendo dos recursos psicológicos do próprio grupo familiar, acomodar e integrar a sua criança. Neste estudo, pais e mães apresentaram sentimentos e reações diferentes frente ao diagnóstico da criança e, na maior parte das famílias, eles tentavam integrar a criança ao grupo familiar, embora negando muitas vezes o diagnóstico.

Algumas das expectativas dos genitores em relação à sua criança com deficiência parecem exageradamente altas e inapropriadas face ao quadro clínico tão complexo acarretado pela SD. Lamb e Billings (1997) relatam haver diferenças entre as expectativas dos pais e das mães. Os pais têm expectativas mais altas para meninos que para meninas. Estas diferenças não foram encontradas nos relatos dos genitores deste estudo, pois tanto os pais quanto as mães apresentaram expectativas semelhantes quanto à escolarização e profissionalização de seu filho/filha com síndrome de Down.

Devido às dificuldades em adequar a criança deficiente mental e a necessidade de cuidados extras, são comuns os altos níveis de estresse, principalmente, em mães (Ali \& cols., 1994; Dyson, 1997; Hornby, 1995; Lamb \& Billings, 1997; Shapiro, Blacher \& Lopez, 1998; Sloper, Knussen, Turner, \& Cunningham, 1991). No entanto, em nosso estudo, os genitores não relataram estresse pelo fato de terem um filho/ filha com SD. Ao contrário, eles relataram sentir-se satisfeitos com a criança, acompanhando, com euforia, cada progresso alcançado por ela. Contudo, é importante lembrar a inconsistência no relato verbal dos genitores discutida anteriormente, que pode explicar essa contradição. Assim, é importante que as pesquisas futuras investiguem as inconsistências entre o relato verbal e não-verbal e os níveis de estresse e satisfação dos genitores.

Os dados observacionais mostram a liderança do pai ou da mãe em detrimento da liderança da criança durante os episódios interacionais, tanto diádicos quanto triádicos. A predominância de comportamentos de "Solicitar/Sugerir", por parte dos genitores, e os episódios pouco freqüentes "Sem liderança" sugerem uma maior diretividade destes 
durante as interações com sua criança com SD, conforme descrito na literatura (Cielinski \& cols., 1995; Corter \& cols., 1992; Lieberman \& cols., 1995; Roach \& cols., 1998). Embora a literatura seja enfática em relação à diretividade das mães, no presente estudo, os pais também tiveram uma alta freqüência de comportamentos de "Liderança" e de "Solicitar/sugerir", indicando que ele foi tão participativo e intrusivo quanto a mãe.

Esta participação ativa do pai também pode ser observada em relação às iniciativas de interação, uma vez que tanto os pais como as mães obtiveram freqüências similares de iniciativas. Este dado é contraditório com os da literatura, cujos resultados indicam que o pai tende a ter mais dificuldades em lidar com sua criança deficiente que a mãe e, por isso, se engaja menos em episódios interativos com ela (Floyd \& cols., 1997; Lamb \& Billings, 1997). Esta contradição pode ser decorrente não somente de diferenças culturais como também do número pequeno de famílias em nosso estudo. Devido à escassez de estudos nacionais e estrangeiros sobre o papel do pai em famílias de crianças com deficiências (Dessen \& Pereira-Silva, 2000), é de extrema importância a implementação de pesquisas que incluam este membro familiar, bem como os demais levando em consideração o contexto social e cultural (Dessen \& Lewis, 1998; Kreppner, 2000; Lewis \& Dessen, 1999; Pereira-Silva \& Dessen, 2001).

As interações das famílias deste estudo foram caracterizadas predominantemente pela "Sincronia" entre a criança e seus genitores, indicando que os comportamentos emitidos, na sua maioria, tiveram uma resposta adequada do receptor, seja a criança ou os genitores. Este dado é coerente com o da literatura, especialmente no tocante à qualidade da brincadeira da criança (Cielinski \& cols., 1995; Colnago, 1991; Roach \& cols., 1998). Portanto, a intrusividade dos genitores parece não ter impedido que houvesse sincronia nas interações, sugerindo uma adaptação entre genitorescriança SD. Esse mesmo padrão foi mantido pelas famílias, tanto em díades quanto em tríades. Porém, algumas diferenças foram observadas, indicando que quando a criança está na presença de ambos os genitores, há um equilíbrio nas taxas de iniciação de interações, bem como de liderança entre os genitores. Portanto, situações triádicas parecem favorecer uma distribuição eqüitativa do engajamento dos membros em interação, conforme destacado por Dessen (1997).

Os resultados do presente estudo apontam na direção de concordâncias e discordâncias com os dados da literatura, sugerindo a necessidade de mais estudos nesta área, especialmente no Brasil. As famílias de crianças SD precisam se estudadas em uma perspectiva que considere o contexto ecológico mais amplo, se quisermos, de fato compreender a Psicologia: Reflexão e Crítica, 2003, 16(3), pp. 503-514 sua dinâmica e funcionamento. Neste sentido, a abordagem bioecológica de Bronfenbrenner (1977, 1979/1996, 1999) mostra-se apropriada, por enfatizar as conexões entre a pessoa e os ambientes em que ela está em contato, os quais são de extrema importância para o seu desenvolvimento. A busca por uma compreensão do desenvolvimento humano de uma maneira mais integrada, abarcando a pessoa e o ambiente e considerando as matizes temporais e contextuais, revelando os processos intrínsecos entre elas, seus níveis de complexidade e de transformações, são as principais características da abordagem bioecológica de Bronfenbrenner.

Muito ainda tem que ser feito em se tratando de pesquisa com famílias de crianças que apresentam algum tipo de deficiência, particularmente no Brasil. É evidente também a necessidade de um apoio psicológico a essas famílias, elaborado com base nas interações familiares, o que facilitaria o processo de integração da criança de forma mais adequada, principalmente, se este apoio vir de programas de intervenção direcionados a essa população específica.

\section{Referências}

Ali, M. R., Al-Shatti, A., Khaleque, A., Rahman, A., Ali, S. M. \& Ahmed, R. U. (1994). Parents of mentally retarded children: Personality characteristics and psychological problems. Social Behavior and Personality, 22, 41-52.

Berger, J. (1990). Interactions between parents and their infants with Down syndrome. Em D. Cicchetti \& M. Beeghly (Orgs.), Children with Down syndrome. A developmental perspective (pp. 101-146). Cambridge: Cambridge University Press.

Bolsanello, M. A. (1998). Interacão mãe-filho portador de deficiência: Concepič̃es e modo de atuação dos profissionais em estimulação precoce. Tese de Doutorado nãopublicada, Programa de Pós- Graduação em Psicologia Escolar e do Desenvolvimento Humano, Universidade de São Paulo. São Paulo, SP.

Brito, A. M. W. \& Dessen, M. A. (1999). Crianças surdas e suas famílias: Um panorama geral. Psicologia: Reflexão e Crítica, 12, 429-445.

Bronfenbrenner, U. (1977). Toward an experimental ecology of human development. American Psychologist, 32, 513-531.

Bronfenbrenner, U. (1996). A ecologia do desenvolvimento bumano: Experimentos naturais eplanejados (M. A.Veríssimo, Trad.). Porto Alegre: Artes Médicas. (Original publicado em 1979)

Bronfenbrenner, U. (1999). Environments in developmental perspective Theoretical and operational models. Em S. L. Friedman \& T. D. Wachs (Orgs.), Measuring environment across the life span: Emerging methods and concepts (pp. 3-28). Washington, DC: American Psychological Association.

Casarin, S. (1999). Aspectos psicológicos na síndrome de Down. Em J. S Casarin, S. (1999). Aspectos psicológicos na síndrome de Down. Em J. S.
Schwartzman (Org.), Sindrome de Down (pp. 263-285). São Paulo: Mackenzie. Cielinski, K. L., Vaughn, B. E., Seifer, R. \& Contreras, J. (1995). Relations among sustained engagement during play, quality of play and mother-child interaction in samples of children with Down syndrome and normally developing toddlers. Infant Behavior and Development, 18, 163-176.

Colnago, N. A. S. (1991). Pares "mães-bebês sindrome de Down": Estudo da estimulasãa e dos aspectos qualitativos da interacăa. Dissertação de Mestrado não-publicada, Programa de Pós-graduação em Psicologia, Universidade Federal de São Programa de Pos-grad

Corter, C., Pepler, D., Stanhope, L. \& Abramovitch, R. (1992). Home observations of mothers and sibling dyads comprised of Down's syndrome an nonhandicapped children. Canadian Journal of Behavioural Science, 24, 1-13. 
Dessen, M. A. (1984). Interacãa pais-primogennito quando da chegada de uma segunda criança na familia: Um estudo de cass. Dissertação de Mestrado não-publicada, Program de Pós-graduação em Psicologia, Universidade de Brasilia. Brasilia, DF

Dessen, M. A. (1992). Efeitos do nassimento de uma segunda criansa no comportamento nas relaçóes entre o primogênito o os genitores. Tese de Doutorado não-publicada, Programa de Pós-graduação em Psicologia: Psicologia Experimental, Universidade de São Paulo. São Paulo, SP.

Dessen, M. A. (1997). Desenvolvimento familiar: Transição de um sistema triádico para poliádico. Temas em Psicologia, 3, 51-61.

Dessen, M. A. \& Lewis, C. (1998). Como estudar a família e o "pai". Cadernos de Psicologia e Educacáa Paidéá, 8, 105-121.

Dessen, M. A. \& Pereira-Silva, N. L. (2000). Deficiência mental e família: Uma análise da producão científica. Cadernos de Psicologia e Educacãa Paidéáa, 10, 12-23.

Dyson, L. L. (1997). Fathers and mothers of school-age children with developmental disabilities: Parental stress, family functioning and social support. American Journal on Mental Retardation, 102, 267-279.

Floyd, F. J., Costigan, C. L. \& Phillippe, K. A. (1997). Developmental change and consistency in parental interactions with school-age children who have mental retardation. American Journal on Mental Retardation, 101, 579-594.

Floyd, F. J. \& Zmich, D. E. (1991). Marriage and the parenting partnership: Perceptions and interactions of parents with mentally retarded and typically developing children. Child Development, 62,1434-1448.

Herbert, E. \& Carpenter, B. (1994). Fathers- The secondary partners: Professional perceptions and fathers' reflections. Cbildren \& Society, 8, 31-41.

Hornby, G. (1995). Effects on fathers of children with Down syndrome. Journal of Child and 5 in Stul

Kreppner, K. (2000). The child and the family: Interdependence in developmental pathways. Psicologia: Teoria e Pesquisa, 16, 11-22.

amb, M. E. \& Billings, L. A. L. (1997). Fathers of children with special needs. En M. E. Lamb (Org.), The role of the father in child development (pp. 179-190). New York: John Wiley \& Sons.

Landry, S. H., Garner, P. W., Pirie, D. \& Swank, P. R. (1994). Effects of social context and mothers' requesting strategies on Down's syndrome children's socia responsiveness. Developmental Psychology, 30, 293-302.

Lewis, C. \& Dessen, M. A. (1999). O pai no contexto familiar. Psicologia: Teoria Pesquisa, 15, 9-16.

Lieberman, D., Padan-Belkin, E. \& Harel, S. (1995). Maternal directiveness and infant compliance at one year of age: A comparison between mothers and infant compliance at one year of age: A comparison between mothers and
their developmentally-delayed infants and mothers and their nondelayed their developmentally-delayed infants and mothers and their nondelayed infants
Marfo, K Dedrick, C. F \& Barbour N (1998). Mother-child interactions and development of children with mental retardation. Em J. A. Burack, R. M. Hodapp \& E. Zigler (Orgs.), Handbook of mental retardation and development (pp. 637-668). Cambridge: Cambridge University Press.

Pereira-Silva, N. L. \& Dessen, M. A. (2001). Deficiência mental e familia: Implicações para o desenvolvimento da criança. Psicologia: Teoria e Pesquisa, 17, 133-141.

Roach, M. A., Barratt, M. S., Miller, J. F. \& Leavitt, L. A. (1998). The structure of mother-child play: Young children with Down syndrome and typically developing children. Developmental Psychology, 34, 77-87.

Rodrigue, J. R., Morgan, S. B. \& Geffken, G. R. (1992). Psychosocial adaptation of fathers of children with autism, Down syndrome and normal development. Journal of Autism and Development Disorders, 22, 249-263.

Schwartzman, J. S. (1999a). O sistema nervoso na síndrome de Down. Em J. S. Schwartzman (Org.), Sindrome de Down (pp. 44-81). São Paulo: Mackenzie.

Schwartzman, J.S. (1999b). Alterações clínicas. Em J. S. Schwartzman (Org.), Sindrome de Down (pp. 82-127). São Paulo: Mackenzie.

Shapiro, J., Blacher, J. \& Lopez, S. R. (1998). Maternal reactions to children with mental retardation. Em J. A. Burack, R. M. Hodapp \& E. Zigler (Orgs.), Handbook of mental retardation and development (pp. 606-636). Cambridge: Cambridge University Press.

Sigman, M., Mundy, P., Sherman, T. \& Ungerer, J. (1986). Social interactions of autistic, mentally retarded and normal children and their caregivers. Journal of Child Psychology and Psychiatry, 27, 647-656.

Sigolo, S. R. R. L. (1994). Análise da interacão mãe-crianca com atraso de desenvolvimento no segundo ano de vida. Tese de Doutorado não-publicada, Programa de Pósgraduacão em Psicologia: Psicologia Experimental, Universidade de São Paulo. São Paulo, SP.

Sigolo, S. R. R. L. (2000). Diretividade materna e socialização de crianças com atraso de desenvolvimento. Cadernos de Psicologia e Educacăo Paidéáa, 10, 47-54

Sloper, P., Knussen, C., Turner, S. \& Cunningham, C. (1991). Factors related to stress and satisfaction with life in families of children with Down's syndrome. Journal of Child Psychology and Psychiatry, 32, 655-676.

Vaughn, B. E., Goldberg, S., Atkinson, L., Marcovitch, S., MacGregor, D. \& Seifer, R. (1994). Quality of toddler-mother attachment in children with Down syndrome: Limits to interpretation of strange situation behavior. Child Development, 65, 95-108.

Recebido: 28/01/2003 Aceite Final: 18/03/2003

Sobre os autores

Nara Liana Pereira Silva é Mestre e Doutora em Psicologia pela Universidade de Brasília na área de Desenvolvimento Humano. É Psicóloga da Secretaria de Estado de Educação do Distrito Federal - Ensino Especial. É pesquisadora do Laboratório de Desenvolvimento Familiar do Instituto de Psicologia da Universidade de Brasília.

Maria Auxiliadora Dessen é Doutora em Psicologia pela Universidade de São Paulo, Pósdoutora em Desenvolvimento Familiar pela Universidade de Lancaster, Inglaterra. É Professora do Instituto de Psicologia da Universidade de Brasília. É coordenadora do Laboratório de Desenvolvimento Familiar e pesquisadora no Instituto Max Planck para o Desenvolvimento Humano, Berlim, Alemanha. 